$\begin{array}{ll} & \text { Etnográfica } \\ \text { etnográfica } & \text { Revista do Centro em Rede de Investigação em }\end{array}$

Antropologia

vol. $13(1) \mid 2009$

Vol. $13(1)$

\title{
Nos braços de um polvo gentil: burocracia, autoridade, cidadania
}

In the arms of a kind octopus: bureaucracy, authority, citizenship

\section{Vanda Aparecida da Silva}

\section{(2) OpenEdition}

\section{Journals}

\section{Edição electrónica}

URL: https://journals.openedition.org/etnografica/1265

DOI: 10.4000/etnografica. 1265

ISSN: 2182-2891

\section{Editora}

Centro em Rede de Investigação em Antropologia

\section{Edição impressa}

Data de publição: 2 maio 2009

Paginação: 173-193

ISSN: 0873-6561

\section{Refêrencia eletrónica}

Vanda Aparecida da Silva, «Nos braços de um polvo gentil: burocracia, autoridade, cidadania»,

Etnográfica [Online], vol. 13 (1) | 2009, posto online no dia 16 maio 2012, consultado o 10 fevereiro 2022. URL: http://journals.openedition.org/etnografica/1265 ; DOI: https://doi.org/10.4000/ etnografica. 1265

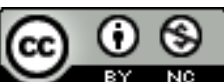

Etnográfica is licensed under a Creative Commons Attribution-NonCommercial 4.0 International License. 


\title{
Nos braços de um polvo gentil: burocracia, autoridade, cidadania
}

\section{Vanda Aparecida da Silva ${ }^{1}$}

\begin{abstract}
Este é um ensaio inspirado em experiências de cidadãos portugueses e estrangeiros, inclusive a da investigadora estrangeira, no trato com órgãos da administração pública do país de acolhimento, Portugal. Minha intenção aqui é compreender alguns dos dispositivos da burocracia na vida cotidiana, discorrendo sobre alguns usos do sentido de autoridade no âmbito das relações sociais. O texto inicia-se com notas de uma "etnografia autobiográfica", enquanto examina estas relações e como podem ser afectadas por dinâmicas complexas de implantação e incorporação de normas burocráticas. O texto traz elementos que contribuem para a compreensão e reflexão sobre os processos de aprendizagem da cidadania, e sobre as manifestações e representações de autoridade numa "situação social".
\end{abstract}

PALAVRAS-CHAVE: burocracia, autoridade, cidadania, administração pública.

\section{O QUE SE SEGUE INICIA-SE COMO NOTAS DE UMA "ETNOGRAFIA} autobiográfica" (Archetti 1999), em que a experiência desta investigadora, na condição de estrangeira, num processo de aprender a conhecer os códigos do cotidiano da Máquina burocrática, soma-se ao conjunto de outras de distintos cidadãos portugueses e estrangeiros. Trata-se de uma abordagem modesta em torno de questões relacionadas com a burocracia, a autoridade e a cidadania, tecida a partir de elementos descritivos ao mesmo tempo que procura construir os parâmetros críticos. Modesta porque, ao buscar olhar mais atentamente para os episódios vividos numa determinada morada da Máquina burocrática do país de acolhimento, me vi na condição de ter que questionar minha

l Agradeço a José Machado Pais e Odilon Vargas Toleto pela leitura da primeira versão deste texto e contribuições, a Simone Frangella por sua atenção na revisão da língua inglesa, ao Vítor Sérgio Ferreira e Roque Felipe O. Filho pelos seus comentários e sugestões. Ressalto que todos aqueles a quem faço agradecimentos não concordarão necessariamente com as idéias tratadas neste texto. 
motivação crítica e a aplicabilidade de minha reflexão. Sobretudo quando o que se passara poderia induzir-nos a pensar que todas as moradas da Máquina teriam as mesmas práticas ou criariam as mesmas dificuldades ao cidadão ou cidadã que dos serviços públicos necessitassem. Ou seja, para que esta reflexão ganhasse em conteúdo qualitativo seria importante conhecer a lei que sustenta as práticas da administração pública do país em questão, e neste momento não se pretendeu investir nessa via.

Pude de seguida constatar que em outras instituições também poderia obter informações sobre situações de vulnerabilidade dos cidadãos. Especificamente, o que se propôs, portanto, foi o desafio de tornar inteligíveis os mecanismos de forças que anulam, modificam e redefinem a experiência social. Assim, neste texto dividido em duas partes, a primeira assumindo um tom de cariz exploratório e a segunda visando uma reflexão ou problematização das situações descritas, se vê que a partir da experiência de um campo não pensado pode surgir um campo possível de investigação.

\section{UMA CACOFONIA ENTRE ESTRANHOS}

A situação estava constrangedora, pois, como estrangeira portadora de um visto de "Investigação/Trabalho - Altamente Qualificado" com duração de 340 dias e de uma Bolsa de Investigação de Pós-Doutoramento da Fundação para a Ciência e a Tecnologia, ${ }^{2}$ já deveria ter um número de identificação fiscal (NIF). Mas não tinha. E porquê?

A condição de ser uma "velha" cliente do Banco do Brasil (no Brasil), e após passar por todos os trâmites internos da burocracia do sistema bancário, mais a contrapartida da Fundação que declarara que eu receberia mensalmente uma bolsa "X", possibilitou-me abrir uma conta corrente naquele banco, desta feita em Lisboa. Logo, ao chegar em Lisboa, pude encontrar o depósito correspondente ao primeiro pagamento do mês do início de minhas atividades de investigação. Portanto, este "dever" de providenciar o NIF poderia ser postergado, uma vez que as bolsas são isentas de impostos.

Desta maneira, a adaptação em Lisboa e o começo das atividades não foram marcados por tantas burocracias. Algumas ficaram no estado de standby. Mas não pude deixar de manter uma certa apreensão quanto ao fato de não ter um NIF, uma vez que, já sabendo de antemão que todo e qualquer cidadão e cidadã que esteja no mercado de trabalho, obtendo rendimentos ou não, passa a ter que declarar-se "isento" ou ver-se às voltas com o respectivo recolhimento dos impostos, não tardaria que pudesse ser interpelada por causa de meu NIF. Ou seja, num certo momento de nossa vida adulta passamos a ter o dever de

2 Atribuída no âmbito do concurso para bolsas de pós-doutoramento (para investigadores nacionais e estrangeiros) da FCT, Portugal. 
existir activamente para o Estado. Em contrapartida, espera-se que este nos assegure o nosso direito. Mas um cidadão ou uma cidadã estrangeiro/a tem direito de existir para um Estado que também lhe é estrangeiro? Será que este Estado (estrangeiro) deseja que este outro exista para ele? Como?

\section{Do mito do existir}

Reza um mito antigo, muito antigo, difundido entre os povos do Ocidente, que seria possível abrir vários mundos, ultrapassar fronteiras, despertar sorrisos ou, simplesmente, encontrar um olhar de cumplicidade entre outros povos de um continente dito civilizado ao fazermos o uso de algumas palavras mágicas: "Bom dia!", "Boa tarde!", "Por gentileza", "Por favor" ou, por fim, "Obrigada/o", "Grato/a". Isto seria o primeiro passo para fazermos alguma solicitação a alguém que vá nos prestar algum tipo de serviço, mesmo que esteja sendo pago para exercer seu ofício. Até porque o processo que se irá iniciar está marcado pela imprevisibilidade. $\mathrm{O} / \mathrm{a}$ estranho/a, neste caso, primeiramente esta narradora, na busca de uma orientação terá que, antes, fornecer também informações prévias a seu respeito. Assim, minhas primeiras características são a aparência física e o meu modo de me portar (Goffman 1993) que, por sua vez, dirão do meu "feitio" inicial.

A busca da mediação, da combinação que seja a mais adequada no processo de interação nas relações sociais, mesmo nos mundos mais massificados e globalizados, é característica do agir das pessoas na vida cotidiana, manifesta através de gestos, palavras, emissão de sinais (Martins 1999). Tinha a ilusão de que para a Máquina burocrática bastava estar consciente de meu dever e querer existir, bastava chegar até um dos seus "fiéis comandados" e dizer-lhe: "Por gentileza, quero tirar o cartão do contribuinte"; ou, "Boa tarde/Bom dia, quero tirar o cartão de contribuinte, o que é preciso?" Esta procura da palavra, da maneira, do gesto correcto expressa também um certo embaraço, numa circunstância específica, mas que traduz uma situação e nesta tem-se, a priori, uma orientação do que é certo e do que é errado, fruto do assentamento da socialização na composição do manual de boa conduta. ${ }^{3}$

E na hierarquia dos mundos mantinha a ilusão de que a difusão de uma vontade individual está assegurada na sociedade moderna, posto que está subentendido que se conhece os direitos cívicos e sociais de cidadania, "l'homme en société". O mito ainda reverberado por vários povos de outros mundos, desejado e invejado, diz ainda que aquele/a que honrar seus compromissos e cumprir os seus deveres descobre outro inimaginável sentimento: o de uma "vida livre

3 "Ele não está escrito, mas está lá, nos diferentes momentos, registrando na consciência cotidiana de cada um o que, sobretudo na conduta dos outros, quebra ou não quebra a normalidade do processo interactivo. É o que nos leva a todos ao papel permanente de coadjuvantes dos relacionamentos em que outras pessoas estão no centro da situação, como protagonistas principais das relações sociais" (Martins 1999: 10). 
e aberta". Para isso, segue o mito, dá-se um outro acontecimento na vida das pessoas que é a consciência do pertencimento, logo, a consciência de que se é responsável por seus actos perante toda e qualquer lei.

Ora, mas e quem deseja, assim, ser tão responsável por seus atos, se é tão mais fácil e vantajoso não ter tantas obrigações, ter quem responda por nós, que não saibam a nossa morada, se o que dissemos é de fato o que dissemos, se o nome que assino é verdadeiramente o que foi inscrito nos documentos de certidão de nascimento, de batismo? Para quê desejar ter tanta consciência de si, quando é tão mais fácil e menos comprometedor não saber de si, pois também isto não implica ter que saber do outro?

Mas não teria como não correr o risco, uma vez que passaram a me questionar e o questionamento daqueles que pediam o meu NIF aumentava a pressão da necessidade e obrigação de existir para a Máquina burocrática da recolha das Finanças. Porém, não me fora dito que para conseguir ser inserida no sistema da Máquina burocrática teria que conhecer os seus tentáculos sugadores.

Como tinha a informação de que as visitas à Máquina são concorridas, saí muito cedo de casa para concorrer ao seu atendimento. Muitas mulheres e homens, vindos de todas as partes, de outros países, outros mundos das ex-colónias, do Terceiro Mundo, e até mesmo pessoas vindas de territórios do Primeiro Mundo, têm que solicitar uma senha que é emitida por uma de suas "máquinas bebés" (baby machines), ${ }^{4}$ ao premir de um de seus botões, conforme as indicações. Destes cidadãos e cidadãs, muitos ficam horas à espera de obter um pouco da atenção de um dos seus "fiéis comandados". Há destes que passam por constrangimentos dos mais agudos, uma vez que - não conhecendo fluentemente a língua dos que são "fiéis comandados", a língua da pátria de acolhimento - perdem-se na dificuldade de comunicar e compreender a informação para uma possível resolução do problema ou, simplesmente, na solicitação da emissão de um documento, uma certidão, um atestado, ou um NIF. Às vezes, perde-se completamente a energia e a vontade e vê-se corpos de todos os tipos e cores, novos e velhos, se arrastando de um lado para o outro, com olhares desolados, perdidos diante dos "guichês" muito parecidos e com números, quase sempre, os mesmos: 01, 02, 03, 04... Mas qual será o que corresponderá à necessidade do solicitante/do cliente...? Correm os olhos dos desolados pelos guichês e perdem-se no medo de perguntar por mais uma informação, na incompreensão de ambos os lados.

Sob esta "aura" estava num dos endereços da morada da Máquina, com a sensação de que estava na "Roda do Destino" a ver qual seria a minha

4 Trata-se de uma nominação figurativa associada à idéia de Máquina burocrática. O sentido figurativo não visa qualquer julgamento acerca de a existência das baby machines nas moradas da Máquina ser "boa" ou "ruim".

5 Sinônimo da Roda da Fortuna; "vista pelos antigos como deusa do acaso, a Roda da Fortuna na Idade Média representava tanto a Roda da Vida, que elevava o homem até o alto antes de deixá-lo [continua] 
sorte naquele dia... Fui à baby machine correspondente à minha solicitação. Todavia, alguma indecisão pairou quando olhei as várias placas e respectivos guichês com seus números entre pequenas separações. Apertava o botão da baby machine correcta...? Vamos ver se há algum/a "fiel comandado/a" por perto para me dizer se estou no local correcto... Nada. Mas a fila também não estava sendo rápida e havia poucos dos "fiéis comandados" a dar atendimento naquele horário.

\section{No limite para existir}

O placar luminoso ressoou piscando mais um número. No bilhete que a baby machine emitira estava marcado: "Data: 16/05/2007, Hora de Entrada: 10:19, Atendimento previsto às:..." - não marcava hora alguma. Havia 100\% de chances de estar enquadrada no tipo de solicitação que estava prestes a fazer. Tinha poucas possibilidades de que não viesse a atender aos requisitos: passaporte com visto, OK; contrato de Bolsa de Pós-Doutoramento da Fundação para a Ciência e a Tecnologia, com declaração do valor da bolsa, OK; até um comprovativo de alojamento tinha à mão, OK. O que poderia dar errado?

Ouvi mais um soar da placa electrónica. Piscou em frente da letra B. Lá estava ele a piscar B 0049. Levantei-me da cadeira com um semblante de breve alívio. Caminhei tentando disfarçar a ansiedade e me preparando para como entoar o meu pedido: "Quero tirar o número de contribuinte". Sentei-me, olhei bem para a "fiel comandada" e disse-lhe: "Bom dia, eu quero tirar o número do contribuinte." Não me recordo se a mulher respondeu ao "bom dia"; entretanto, foi incisiva no pedido de meu passaporte. Imediatamente saquei de minha pasta o passaporte e demais documentos que tinha à mão. Ela olhou o passaporte, viu que tinha visto, estranhou o tipo de visto, mal olhou o contrato de bolseira da Fundação, abriu o passaporte na folha de carimbos de entradas e saídas do país de acolhimento e disse-me: "Não tem 183 dias de permanência dentro de Portugal; esteve no Brasil e voltou... Isto já não dá 183 dias corridos neste ano de 2007, dentro de Portugal, não confirma que reside em Portugal." Pergunto: "Como assim, mas eu tenho residência em Lisboa, tenho como comprovar?" Ela insiste: "Não tem 183 dias residindo em Portugal. Necessita de um representante fiscal que resida em Portugal e venha com você aqui e traga o NIF e o BI [bilhete de identidade]. Aí não haverá problema, damos-lhe o NIF."

Minha palidez deve ter ficado evidente, tal era o meu desapontamento após ter estado sentada por quase duas horas. Faltava-me a saliva. Provavelmente a mulher, por algum sentimento de solidariedade, quis tentar atenuar

cair de novo, como a Roda do Acaso, que não parava nunca de rodar e indicava a mudança perpétua que caracteriza a natureza humana" (Costa e Zierer s/d.). No Tarot corresponde à X Carta e sua representação está associada à mudança, ao inesperado. 
meu semblante desolado e prontificou-se a atender-me sem ter que me submeter a outra fila de espera, com a condição de que eu aparecesse naquele dia ainda, ou, mais tardar, na manhã seguinte com o meu representante fiscal. Pode parecer ironia, mas perante a certeza que advém de ter $100 \%$ de chances de conquistar alguma coisa, neste processo de aprendizagem das regras de um Estado estrangeiro (para mim), vi-me contrariada em todas as lógicas da estatística.

\section{Não serei a única no estado do quase-existir}

Todavia, a sensação de uma passividade aprisionadora chocava com a minha indignação. Isto me colocou entre o estado de choque e o espanto. Pelas ruas comecei a tecer as mais variadas conjecturas: será que é pelo fato de ser brasileira?, terá posto em causa o meu visto?, será racismo, preconceito?, pronto, serão reais as dúvidas que pairam acerca da mulher brasileira... mestiça, mulata... e ainda por cima solteira?, será que terei que me casar, agora, com um português?, mas será que tem que ser um português legítimo?, será que terá que apresentar os resultados das análises de sangue para comprovar que é português, mesmo? Estaria se passando o que acabara de se passar comigo? Não. Experiência semelhante também fora vivida por outras pessoas, como na narrativa do trecho a seguir:

Cheguei à Loja do Cidadão ainda com muito sono às 9 e meia da manhã. [...] Hoje consegui pegar uma senha para ser atendida [...]. Da primeira vez que fui até lá, não havia mais senhas. Na realidade, eu nem sabia que teria que fazer esse tal de NIF. [...] Espera-se muito nesse lugar. Bem, consegui ser finalmente atendida às 10:40. Dirigi-me ao guichê e expliquei à atendente que gostaria de fazer meu NIF [...]. Para minha surpresa, ela disse que somente poderia fazê-lo com o acompanhamento de um cidadão português. Por um instante, perdi o chão. Como alguém que chega a um país estrangeiro pode apresentar um cidadão deste mesmo país, uma vez que possivelmente não conhece ninguém? Argumentei, afinal, que era estudante, que ficaria em Lisboa somente por alguns meses, que tinha todas as autorizações possíveis e imagináveis, mas a profissional foi irredutível. Fiquei muito chateada com esta situação. E agora? Tudo bem, que até conheço uma pessoa que poderia me acompanhar. Mas seria certamente uma perturbação. Resolvi ir embora sem discutir e pensar de que forma poderia concretizar esse processo sem ter que perturbar terceiros [...] (trecho do diário de campo de Rozeli Maria Porto, de 05/04/2007). ${ }^{6}$

6 Agradeço a Rozeli Maria Porto, antropóloga brasileira, por ter me cedido os trechos de seu diário de campo. 
Tinha a obsessão de que teria que ter este tal NIF e sentia um certo alívio, uma vez que, felizmente, tinha a quem recorrer (quando muitos não têm). Porém, aquilo tudo sinalizava que alguém seria incomodado, uma vez que teria que deslocar-se de sua residência ou trabalho para me socorrer para algo que, a priori, não deveria ser um procedimento com implicação de outrem. Tal procedimento não era apenas para a obtenção do NIF; fui informada que era usual para o atendimento de outros tipos de solicitações em outras moradas da administração da Máquina do Estado.

Tal dinâmica perversa coloca-nos, então, estrangeiros/as e cidadãos e cidadãs do país de acolhimento, enlaçados pelos braços de um polvo gentil, porém sutil, uma vez que no seu abraço lentamente exclui-nos ao criar tantos obstáculos para que se obtenha o que quer que seja, ao mesmo tempo que transforma os/as cidadãos/ãs em "fiscais" uns dos outros, os neutraliza e os "apaga" na dependência mútua para estar em dia com o dever cívico, logo, de saber-se pertencente, saber-se cidadão/ã. Se para mim é ruim, isto já foi pior...; ou então, poderia ser pior... Consolemo-nos, então, com desabafos no café. ${ }^{7}$

Entre desabafos e tentativas de compreender e apreender quais eram os códigos ou as "normas" do jogo, outros trechos do diário de campo da citada antropóloga vêm a somar neste aprendizado:

Retornei então à Loja do Cidadão. Peguei a senha de número 285 sendo que naquele momento a senha para atendimento era de 174. Aguardei por quase 3 horas para ser atendida. E o pior era que não sabia que iriam fazer o meu NIF porque das outras vezes que estive lá a atendente exigia a presença de um cidadão português para que eu pudesse fazer o documento. [...] Não fui atendida pela mesma funcionária dos outros dias, felizmente. Esta me pediu o passaporte e o endereço. Nada mais. Fez o cartão para mim sem falar em nenhum cidadão português. Sem nenhum problema. Fiquei feliz e com muita raiva da outra atendente. Ela me fez perder três tardes naquele lugar estressante. Cheguei lá às 3 e saí às 6. Fui embora para casa então (trecho do diário de campo de Rozeli Maria Porto, de 13/04/2007).

De toda forma, confrontava-me com um sentimento ambivalente, pois, ao mesmo tempo vinha a consciência de que estava momentaneamente privada de cumprir meu dever, porque este direito não me fora dado, estava "temporariamente fora de serviço"; havia outras informaçóes concorrentes que minavam a iniciativa de contestar, de reclamar, uma vez que colocavam em mim a dúvida quanto ao procedimento ter sido, exactamente, aquele para comigo: "Ora, mas isto é uma coisa tão simples", diziam-me alguns; "Fulano/a esteve aqui e não

7 Sou grata à Graça Silveira e Ricardo Ruas, amigos e cidadãos portugueses, pelas motivações e conversas inspiradoras. 
se passou nada, foi só chegar ao guichê e pronto!"; "Ah, deve ter-lhe fornecido informação errada..." No SEF (Serviços de Estrangeiros e Fronteiras), outro comentário: "Isto deve ser algum disparate" . Às tantas, tinha dúvidas se havia interpretado correctamente as palavras da "fiel comandada".

Foi então que resolvi arriscar um telefonema ${ }^{9}$ para outra morada da Máquina e ouvi, do outro lado, uma voz quase metálica: "A senhora tem que ter um representante fiscal..." Pergunto: "Isto é legal?". E ouço a voz: "Esse tipo de informação não é connosco, esta é a informação que temos." Se é fato que para se viver no espaço do outro é necessário aceitar as suas regras, neste território da Máquina de tantos tentáculos e cujos micro-obstáculos me jogavam de um lado ao outro, qual era a variável que me vulnerabilizava? Essa pergunta era feita também por outros cidadãos/ãs "estrangeiros/as" de nacionalidade brasileira que, como eu, queriam apenas compreender:

Todavia, não conseguia entender as regras desse jogo perverso. Não existem regras. É um jogo de cara ou coroa. Dependendo do estado de espírito da funcionária, ela faz ou não o documento. Conversando com outros pesquisadores brasileiros, descobri que eles passaram pelo mesmo processo. Só que eles exigiram fazer o documento na mesma hora e foram até à gerência. Segundo meus amigos, a gerente baixou uma ordem para que os atendentes fizessem o NIF sem a necessidade de um cidadão português. Mesmo com este arranjo, pareceu-me que a ordem perversa no que diz respeito ao atendimento prevaleceu neste órgão. Algo que se pode resolver para uns e não para outros. Uma regra a partir de estereótipos desestereotipados... (trecho do diário de campo de Rozeli Maria Porto, de 13/04/2007)

\section{... Atendimento lento ${ }^{10}$}

$\mathrm{Na}$ crescente consciência das relações e códigos que não eram visíveis a olho nu, no cotidiano do mapa social dos/as cidadãos/ãs do país de acolhimento, começava a desprender-me de meus sentimentos de perplexidade, porque a experiência de não existir para a Máquina das Finanças, por vezes, é cómoda e leva-nos a ficar livres das dificuldades burocráticas, para dar início à tentativa de jogar com as regras do Outro. Diante deste meu novo processo de aprendizado, que mais fortalecia minha idéia e sentimento do que é ser cidadão/ã, de não ser mais uma "mais igual do que outros", via-me às voltas com colegas do Instituto de Ciências Sociais da Universidade de Lisboa, entre manifestações

8 Disparate: “acto irreflectido ou impróprio; absurdo; tolice” (Dicionário da Língua Portuguesa, Porto Editora, col. Dicionários Académicos, 2006, p. 278).

9 Até com um certo sotaque do português de Portugal, na expectativa de ver se era um problema de percepção através da voz, de minha condição de estrangeira...

10 Talvez as palavras não fossem exatamente estas, mas a informação era. 
de solidariedade, a tentativa de achar um tempo (no horário de expediente) e ver quem poderia exercer o papel de meu/minha "representante fiscal". ${ }^{11}$

No âmbito das relações que se constituem no terreno das organizações públicas, outros aspectos servem-nos de exemplo. Ao supormos que os "fiéis comandados" estão para "servir o povo" e estes, por sua vez, posicionam-se de maneira indiferente, se aquele/a que os procura, o/a "cliente", recorrer a outra morada da Máquina, poderá encontrar algo semelhante. Aliado a isto ocorre mais uma crescente na tensão: o/a cliente ${ }^{12}$ (em Portugal é denominado "utente" $)^{13}$ tem a idéia, na maior parte dos casos, de que o seu "problema" é sempre o mais importante, acirrando-se mais quando o/a "fiel comandado/a" e o cliente julgam-se superiores socialmente e chocam-se nos seus status sociais (Merton 1966). Para além disso, à nominação que classifica todas as pessoas que necessitam dos serviços e bens públicos ou privados - utente - corresponde a idéia de que "não pagam" por estes serviços, logo, a "estes" se "dá" atendimento, enquanto que, subterraneamente, ocorre o contraste com a representação de "cliente" que é aquele/a que paga, que frequenta periodicamente e estabelece algum vínculo mediante pagamento. Ora, cliente ou utente, não pagam ambos à Máquina? ${ }^{14}$

Novamente, pela segunda vez, compareço à outra morada da Máquina das Finanças, desta vez acompanhada de meu "representante fiscal". ${ }^{15}$ Ao lado da baby machine um papel escrito em caneta colorida dizia-nos: "sistema oscilante... atendimento lento". Fomos embora. No terceiro dia, retornei com meu "representante fiscal”, mais uma vez, à morada da Máquina. Não tardou e o placar ecoou sinalizando o nosso número. Caminhámos até o guichê e desta vez, para atender-nos, tínhamos um "fiel comandado". Dirigiu a palavra ao meu "representante": "O senhor é o representante? O seu cartão de contribuinte e o seu bilhete de identidade", pediu-lhe com o semblante mais impassível e austero, provavelmente dada a percepção de minha condição de "estrangeira", minha

11 Não conseguia desprender-me da imagem de que o representante fiscal faria o papel de meu/minha "tutor/a" ou "fiador/a".

12 Recorro aqui ao significado de "cliente" no dicionário: "pessoa que compra algo; freguês; pessoa que utiliza os serviços de um profissional (médico, advogado, etc.) mediante pagamento; pessoa que faz as compras sempre no mesmo sítio ou que frequenta habitualmente o mesmo local" (Dicionário da Língua Portuguesa, Porto Editora, col. Dicionários Académicos, 2006, p. 180).

13 Utente: "pessoa que utiliza bens ou serviços públicos ou privados" (Dicionário da Língua Portuguesa, Porto Editora, col. Dicionários Académicos, 2006, p. 818).

14 Em recente divulgação, em rede nacional, a imprensa portuguesa anunciou os resultados de um estudo encomendado à Universidade Católica pelo Instituto Nacional de Administração (INA). Neste inquérito, os cidadãos portugueses consideram que o Estado presta um "serviço pior" ou "muito pior" do que o do sector privado, diz a reportagem cuja chamada é "Portugueses querem dinheiro bem gasto" (Diário de Notícias 2007).

15 Meu sincero agradecimento ao colega dr. António Martinho por ter me acompanhado nesta empreitada. 
"diferença cultural" afirmada pela presença de meu colega ao acompanhar-me e, talvez, dada a minha imagem mestiça, ${ }^{16}$ ou, além disso, correspondendo a uma característica peculiar da estrutura da Máquina, cuja orientação incentiva seus "fiéis comandados" à "ênfase no carácter impessoal nas relações” (Merton 1966: 106; Weber 1966).

Meu colega não teve tempo de tomar qualquer posição que fosse, a não ser a de atender àquela "ordem". Poderia ter entrado muda e saído calada, porque nada me fora perguntado. Tudo o que interessava o meu solidário colega e "representante" forneceu. Inclusive, o seu endereço passou a ser temporariamente o meu, pois, para os registos da Máquina, passei a "existir" (residir) na morada de meu "representante". Portanto, para a morada dele seria remetido o meu cartão do contribuinte. O que mais poderia querer, se as mulheres portuguesas não estão imunes dos paradoxos de viverem num país que lhes diz que há igualdade entre homens e mulheres, enquanto na vida cotidiana se insiste em condicionar este direito? Qual ou quais a(s) garantia(s) para a Máquina?

Algumas questões podem ser aventadas, mas a primeira que me dizia respeito com aquele não-registo de minha morada, em Portugal, tinha a seguinte mensagem: coloque-se no seu "não-lugar". ${ }^{17}$ Reclamava a minha condição de "estrangeira-imigrante", porém, confrontando meu reclamar por uma relação, um pertencimento. Esta é a ambiguidade: que a idéia de "viajante" não poderia ser interpretada como definitiva dada a condição do trânsito, uma vez que a possibilidade do "viajante" é ter para onde retornar; o sonho acalentado é, em muitos casos, ter e manter uma segunda residência (Augé 1994).

A segunda, implicava mais o meu colega "representante", que, a partir deste episódio, foi chamado à responsabilidade de me recomendar perante a Máquina, mas, sobretudo, à certificação de que me portaria bem. No contexto em que a posse de tal documento seria meu dever perante a sociedade, a necessidade de ter uma "testemunha" para a efectivação deste dever pode pressupor

$16 \mathrm{Na}$ análise de duas sondagens realizada pelo Observatório da Imigração, no item "A relativa consolidação da norma anti-racista", é observado que "o principal aspecto que ressalta do estudo destes indicadores de racismo declarado é que a grande maioria dos inquiridos revela atitudes de aceitação dos estrangeiros. Trata-se de um resultado previsível, num contexto social em que, como se afirmou, a xenofobia e o racismo declarado têm vindo a ser vilipendiados. Segundo a ideologia corrente, a uma nação que deu 'novos mundos ao mundo' e que sempre se orgulhou da miscigenação conduzida em tempos de colonização e dos 'brandos costumes' que nos 'caracterizam', não ficaria bem ser racista, não só em termos de percepção de si como de comportamentos efectivos perante o diferente" (Lages et al. 2006: 265-266).

17 Marc Augé (1994) vê a questão do "não-lugar" como condição da contemporaneidade. Para este autor, "o não-lugar" se refere à condição do viajante, daquele que está em trânsito, portanto, aquele que liga e articula o "espaço antigo e o espaço moderno". Esses espaços são materializados nas auto-estradas, estações de comboios, aeroportos, etc. 
também um pacto de (des)confiança, ${ }^{18}$ ou, ainda, uma "cidadania tutelada" e "afiançada". ${ }^{19}$ Deste modo, nos comprometia um ao outro, nesta cumplicidade sob matizes das relações econômicas ou mercantis. Isto, por certo, remonta aos nossos vínculos, remete-nos à história, cultura e língua comungada, e data da era colonial (Feldman-Bianco 2002: 167-168).

Entretanto, prosseguir na argumentação unilateral de que esta sociedade é tão-somente discriminatória e racista com os/as imigrantes, os/as estrangeiros/as, não faz jus às experiências cotidianas de distintos cidadãos e cidadãs portuguesas, uma vez que, ao que tudo indica, ninguém está isento da ação da Máquina... O relato da experiência de um outro cidadão ${ }^{20}$ pode nos fazer pensar mais sobre tal observação, principalmente quando a idéia de "fuga ao fisco" lança fumaça de desconfianças. Trata-se de um homem branco, sexagenário, membro da elite intelectual que, após ter sido internado e tratado num hospital público da cidade de Lisboa, em sinal de gratidão pelo atendimento, mas principalmente por sua cura, resolveu fazer a doação de uma determinada quantia em dinheiro. Tal doação destinava-se à compra de um novo equipamento para o hospital. Passado algum tempo, este mesmo homem compareceu à Máquina para lhe declarar toda sua movimentação financeira, incluindo a informação documentada de que havia efetuado uma doação (em dinheiro) ao Hospital "X". Diante de uma das "fiéis comandadas" ouviu a seguinte frase: "Mas o senhor doou isso tudo?!" "Doei”, disse o homem. "Ah, mas então o senhor será chamado para esclarecer isto!" "Mas por quê? Todos os papéis estão aí!" "Mas mesmo assim, o senhor terá que explicar como doou este dinheiro todo." Nos dias que correm sabe-se que o referido homem foi chamado para justificar o seu acto e a "funcionária" descobriu que a declaração não era adequada porque não mencionava a legislação ao abrigo da qual o donativo tinha sido oferecido. E mais: também não dizia que o doador não tinha recebido nenhuma contrapartida. Por tudo isso seria necessária uma nova declaração. E aí começou outra história da família das anteriores, para conseguir que o hospital "X" lhe passasse uma declaração adequada, o que aconteceu ao fim de doze dias.

A pergunta poderia ser, então, com que autoridade a "fiel comandada" questiona e constrange o homem que declarava sua doação? Será por desconfiança

18 Numa outra direç̧ão, pode ser interpretado como um modo de "vigilância espontânea" exercido pela própria necessidade de localizar as pessoas através de outrem, logo, possibilitando à gestão pública a "normalização dos comportamentos" (Foucault 2006). Uma vez estabelecido tal pacto de confiança, ficam atreladas ao outro ou na dependência (in)voluntária de outra pessoa. No caso das mulheres estrangeiras-imigrantes, fica também a marca de que não são vistas como "protagonistas" para a sociedade de acolhimento, podendo estar vulneráveis e na condição de vítimas (Declaração de Rivas 2006).

19 Agradeço aos investigadores e amigos doutores José Manuel Rolo e Vítor Sérgio Ferreira pela lembrança sugestiva dos respectivos conceitos.

20 Trata-se de um cidadão português, casado, no topo da carreira. O depoente pediu para ser mantido o anonimato. 
da origem do dinheiro do citado cidadão português? Ou terá sido, mesmo, uma investida de autoridade que reclamara para si todo o poder da Máquina?

\section{PARA ALÉM DE UM CASO INDIVIDUAL}

A experiência do incidente de ver-se impossibilitado de obter um simples documento ou ser exaustivamente testado na resolução de algum problema por empecilhos atribuídos à tecnologia pode servir-nos para ampliar o leque interpretativo para pensar a sociedade em questão, bem como as relações com a população e o papel da burocracia. Para Michel Foucault, "as relações de poder, os factos de dominação, as práticas de sujeição não são específicos aos totalitarismos, também atravessam as sociedades ditas democráticas" (2006: 295). Nestes termos, apesar do exemplo singular que detona tal reflexão, a sutileza dos mecanismos de sujeitar a população às mais variadas situações, por vezes perversas, exige das pessoas - oscilando o grau de dificuldades em função da literacia, da situação financeira, da língua, do estado de saúde ou de velhice - o exercício abnegado ou angustiado de perseverar ou abandonar a busca pela resolução de seus problemas ou reivindicações. Assim, a "percepção da diferença cultural" (e também de classe ou género) pode ser um indicador de discriminação ou preconceito que na relação poderá ocorrer dos modos mais sutis, sem serem passíveis da "sanção social".

O fato de a gerente ter tido a iniciativa de emitir uma "ordem" para que os atendentes (os "fiéis comandados") fizessem o NIF (aos "estrangeiros/as") sem a presença de um cidadão português, conforme o relato de campo da investigadora citada, suscita outra indagação. Por quê os "atendentes" não aderiram, então, à continuidade do cumprimento da "ordem"? Temos aí mais uma boa pista. Pensadores como Max Weber, que tratou a burocracia, ou Robert Merton, sobre a relação entre a burocracia e a personalidade, são convidados inspiradores para avançar nesta base empírica. A idéia de "costume" pode ser interessante para reflectir acerca da ordem emitida e, posteriormente, não mantida. Em Weber, o "costume" está em oposição à "convenção" e ao "direito", de tal modo que este é uma regra que pode, por vezes, não ser seguida ou garantida. O "costume" impõe uma conformidade com a maioria, uma vez que a "'validade' de uma ordem significará, pois, para nós mais do que uma simples regularidade condicionada pelo costume ou por uma situação de interesses, do decurso da acção social" (Weber 2005: 54).

Robert Merton observa que dentro da burocracia há "disposições para inculcar e fortalecer sentimentos” (1966: 101) que farão com que o/a funcionário/a possa manipular ou moldar o seu grau de submissão a uma "norma" (ou "ordem"). A pressão que a estrutura da Máquina exerce sobre o "fiel comandado" para que este seja "metódico, prudente, disciplinado" no cumprimento de suas funções é necessária também no âmbito da própria estrutura social, 
desencadeando a existência de "fortes sentimentos que assegurem dedicação aos próprios deveres, uma aguda percepção dos limites da própria autoridade e competência e a realização metodizada das actividades de rotina" (Merton 1966: 101). Deste modo, a disciplina torna-se, na visão de Merton, um "fim em si mesmo" que "produz a rigidez e a incapacidade de ajustamentos imediatos" (1966: 102), impossibilitando a resolução dos problemas dos cidadãos e cidadãs. Uma "ordem" dada por um superior sem uma base que assegure aos "fiéis comandados" a confiança no seguimento desta "ordem", não chegará à "convenção", ao "direito" (Weber 2005). Será que, no âmbito da estrutura da Máquina, a inadequação da orientação não potencia a resistência dos/as "fiéis comandados/as" à eficiência, sobretudo diante dos casos particulares? Qual a variável que vulnerabiliza (a mim e) tantos/as (outros/as) cidadãos/ãs?

Tal variável é ser "estrangeiro/a" e esta identificação está atrelada a outra variável que é a da "vulnerabilidade". Esta, por sua vez, é contextual e contingente, pois resulta de subjetividades no cerne de ambíguas, porém, dinâmicas relações de poder no cotidiano das pessoas, ora pendente para um lado ora para outro, com maior ou menor inflexão, flutuando e modificando-se. A vulnerabilidade pode ter cor, sexo, classe e, talvez, idade, mas, neste caso, o meu aprendizado foi que dentro dos 99\% de percentagem que poderia indicar "positividade" (posto que tinha a documentação em dia e estava em condições legais), havia um elemento classificatório que exigiria a necessidade de negociação: era "estrangeira". Tal como tantos outros cidadãos e cidadãs, portanto, não estava isenta de micro-obstáculos que teria que negociar diante dos recursos de poder apresentados, deveria demonstrar meu desempenho e responder aos "reflexos de obediência", enquadrando-me conforme o "funcionamento tecnológico dos serviços" (Gil 2004). Quando eles funcionam.

Entretanto, se as recordações de cidadãos e cidadãs portugueses emigrados para o Brasil e brasileiros emigrados para Portugal remetem para experiências que ao serem relembradas marcam sentimentalmente, também é fato que o processo de adaptação a toda e qualquer nova situação marca-nos, inicialmente, no plano dos sentimentos. Desta maneira, é recorrente que a primeira expectativa do/a imigrante que se encontra legalizado/a, originário/a de país cuja expressão linguística é a portuguesa, seja a de receber tratamento diferenciado - se não pela língua comum, ao menos pela condição de legalizado/a.

Em contrapartida, para os/as cidadãos/ãs do país de acolhimento, neste caso, Portugal, pertencente à União Européia (UE), as expectativas se sobrepõem e intensificam-se dado o processo de sucessivos contratempos na adaptação deste país quanto ao seu estilo de relacionar-se com a UE e com o mundo (Feldman-Bianco 2002; Cabral 1992). Todavia, o Tratado de Roma, redigido em 1957 e um dos pilares fundadores da UE, assentava nos princípios da "igualdade de tratamento e da não-discriminação [que] constituíram o primeiro factor originário de um sentimento de pertença a uma mesma comunidade política, o que 
alberga em si a idéia de cidadania, pelo simples facto de que qualquer europeu tinha o direito de ser tratado da mesma forma que os nacionais do país onde se encontrasse, o que fazia esmorecer a noção de 'estrangeiro'" (Mendes 2004: 175). Nos dias atuais, as manifestações de estigma contra o imigrante-estrangeiro influenciam nos processos sociais e desencadeiam dramas sociais ${ }^{21}$ que, por sua vez, também são vividos por nacionais, cidadãos/ãs portugueses ou vindos dos países africanos de língua oficial portuguesa, os PALOP (Gusmão 2004; Vala, Brito e Lopes 1999), imigrantes do Brasil ou países do Leste europeu. ${ }^{22}$

\section{(Não) Somos iguais na diferença}

E o que é ser um/a cidadão/ã no espaço da União Européia? Falar em ser cidadão/ã é recobrar a idéia de pertencimento e de direito. Assim, se recorrer à definição clássica encontro o seguinte: "é ter direito à vida, à liberdade, à propriedade, à igualdade perante a lei; é ter direitos civis, [...] votar, ser votado, ter direitos políticos" (Mendes 2004: 174). Todavia, numa democracia não há direitos civis sem a garantia dos direitos sociais, tais como "o direito à educação, ao trabalho, a um salário justo, à saúde, a uma velhice tranquila" (2004: 175). Logo, poder gozar de todas as conquistas dessa riqueza colectiva que é fruto de um longo processo histórico é saber poder exercer os direitos civis, políticos e sociais, é viver a cidadania plena que, por sua vez, é a prática democrática. Mas quando as pessoas não podem gozar das conquistas da sociedade ocidental e vêem-se privadas de seus direitos?

Tal indagação pode remeter para um pensamento de que uns são mais iguais do que outros e estes outros são aqueles que a priori não correspondem, de alguma forma, ao estabelecido. Muito além da questão de raça, aquele ou aquela que esteja fora da "norma" pode ser vítima de um processo e vir a ser impelido/a à marginalidade, a viver à margem. Aquele ou aquela que se veja impedido de ser um membro activo/a, actuante de uma comunidade, não pertence a esta, logo, não é cidadão/ã. Assim, alojado nas entranhas das instituições, o racismo permeia também outras relações, a saber, as de género e as de sexualidade. As suas manifestações podem ir da violência física, em casos de machismo ou homofobia, à violência mais sutil e silenciosa, a psicológica, manifesta na indiferença à velhice ou para com o portador de necessidades especiais, ou ainda na xenofobia.

Também é fato que nem todas as sociedades estão suficientemente preparadas para exercitar a democracia, desconstruir relações contaminadas de

21 A referência a esta categoria vem de Victor Turner (1975).

22 Estes, embora com legalidade por serem de um país membro da UE, no processo de integração no país de acolhimento e, muitas vezes, devido a situações de precariedade e abandono, adquirem a categoria de "estrangeiro", sendo vistos e tratados como "imigrantes", conforme estudos do Observatório da Imigração (Lages et al. 2006). 
sujeição e construir relações de cidadania. Para tal é necessário o conhecimento e o aprofundamento das práticas democráticas, implicando, assim, o reconhecimento do poder não mais unilateral, mas bilateral. Daí se pressupõe que haja o diálogo (a negociação) nas relações sociais ou, como coloca José Gil (2004: 37), o encontro entre o "conhecimento da democracia" e a "prática democrática", algo que para este pensador se encontra em estado de divórcio. ${ }^{23}$

Dizer que poderia não ser necessária a presença física de pessoas, moradores de uma determinada parte do país de acolhimento, implicadas no ato de terem que testemunhar para efetuar a retirada de qualquer documento de que tem o dever de ser portadora toda pessoa que trabalha, reside ou venha a querer realizar um casamento com um/a nacional, eventualmente pode não soar bem aos ouvidos disciplinados. Entretanto, a dificuldade para se estar em dia com as obrigações, ou reclamar qualquer direito no interior da Máquina, restringe a possibilidade de que os nacionais também possam aceitar que as dificuldades sejam "abrandadas" aos/às "estrangeiro/as". É como se questionassem: "Como dar ou facilitar os direitos aos imigrantes, quando para nós é difícil tê-los?"

Numa "situação social" em que se julga poder dar ou retirar algo a outrem, tem-se um processo interativo entre os participantes que devem proceder à observação de algumas normas de "decência" e "justiça". As pessoas são chamadas a observar tais normas em diferentes situações sociais, sendo que ora uma e outra poderão ter maior implicação, ora, noutra ocasião, uma e a outra serão descabidas. Entretanto, as situações sociais implicam em performances, atos de encenação não para expressar fingimento, mas para as pessoas representarem aquilo que elas julgam ser (Martins 1999). Isto implica ainda uma certa construção, uma lapidação no bojo do processo de interação social em que os participantes aprimoram tal desempenho; há uma responsabilidade mútua entre os envolvidos e, caso haja uma falha de um destes, poderá ser criado um constrangimento que estender-se-á aos demais participantes.

Nestes termos, pode-se pensar sobre a idéia de autoridade, sobre o modo como ela é expressa nas situações mais simples do cotidiano, do que ressalta uma certa ordem ou a necessidade de controlo nos (dos) relacionamentos entre as pessoas. Para tanto é necessário não deixar de falar da "justiça”, da "força", mas sobretudo para destacar que, quase sempre, falar em autoridade é considerar que há uma força legitimadora - pode ser moral ou física, mas há

23 Pina Cabral também observa que a "democracia" pode ser entendida como uma "tradução"/“negociação”, pensada a partir do local em que se constituiu, no "exercício do governo legitimado" que, por sua vez, implica a aceitação por parte daqueles que o legitimaram. Portanto, escreve o autor, “[...] essa negociação não pode ocorrer no vazio, em teoria. Ela deve ser feita entre agentes individuais ou coletivos historicamente situados." Assim sendo, Pina Cabral salienta que os "agentes sociais" não são livres para exercerem o que pensam ser o melhor, por serem “[...] pessoas-coisas, radicadas em lugares específicos, constituídas como pessoas sob formas diferenciadas e, por isso, por relação a espaços específicos - também eles, por sua vez, construídos” (2005: 156). 
uma força. Acreditar na autoridade enquanto exercício da força pode ser um princípio de crença marcado pelo que Montaigne denominou de "fundamento místico da autoridade" (Derrida 2003). Trabalhar com tal fundamento é oportuno porque pode levar-nos para um outro elemento muito importante, que é o "costume". ${ }^{24}$ Este, por sua vez, pode ser mantido por várias gerações numa sociedade em movimento, posto que atrela-se à memória, às bases da socialização e da construção das identidades pessoais e colectivas. Sobre a expressão "fundamento místico da autoridade", Derrida escreve o seguinte:

[...] um, diz que a essência da justiça é a autoridade do legislador, outro, a comodidade do soberano, outro, o costume vigente; e isto é o mais certo: nada, segundo a estrita razão, é justo por si; tudo se altera com o tempo. O costume faz a equidade, pela simples razão de ser recebido; tal é o fundamento místico da sua autoridade. Quem a reconduz ao seu princípio, aniquila-a (2003: 21).

Derrida destaca que Montaigne, que distinguia o direito (as leis) da justiça, dizia que a autoridade das leis era tal que "[...] quem lhes obedece por elas serem justas, não lhes obedece justamente por onde deve" porque "[...] as leis mantêm-se credíveis, não por serem justas, mas por serem leis" (Derrida 2003: 21). As leis têm autoridade, elas têm um crédito de crença que lhes é dado e é por isso que, de meu ponto de vista, a noção do costume pode abrir uma brecha para a compreensão do modo como as pessoas podem se apropriar, através das práticas/ações, do sentido de autoridade ou de extensão de autoridade numa "situação social".

A oscilação do uso e abuso da autoridade enquanto forma de constrangimento moral ou físico, através da violência, pode servir para pensar sobre as atitudes protetoras, abusivas e arbitrárias quando se sentem os tentáculos de uma Máquina burocrática, por exemplo. Será que mudar um costume é ter que desconstruir uma idéia de direito, é modificar mentalidades, visão de mundo, modos de ver e ser? O Tratado de Amsterdã (de 1997), que nasce com o propósito de criar uma Europa dos Cidadãos em detrimento de uma Europa dos Estados, destaca ainda o princípio da não-discriminação (artigo 13..$^{\circ}$, com objetivo de combater "a discriminação em razão do sexo, raça ou origem étnica, religião ou crença, deficiência, idade ou orientação sexual" (Mendes 2004: 177). Este é um princípio geral da igualdade, mas o que acontece quando os "fatos sociais" não corroboram as leis e corroboram costumes,

24 ' $[\ldots] \mathrm{O}$ 'costume', nas sociedades tradicionais, tem a dupla função de motor e volante. Não impede as inovações e pode mudar até certo ponto, embora evidentemente seja tolhido pela exigência de que deve parecer compatível ou idêntico ao precedente. [...] A decadência do 'costume' inevitavelmente modifica a 'tradição' à qual ele geralmente está associado” (Hobsbawm 1997: 10). 
como a prostituição e o tráfico de mulheres e menores para fins de escravidão? Será que há diferença? E quando a dimensão do poder joga com a dimensão subjetiva das pessoas que executam as leis? Como tratar a dualidade existente entre os representantes da Máquina que se colocam como autoridade ao mesmo tempo?

Se retomar as experiências vividas quando tentava obter o meu NIF e recuperar a imagem do "fiel comandado" com seu semblante austero e indiferente, aliando-as à experiência do cidadão português que fizera uma doação ao hospital "X", com a "fiel comandada" na sua atitude de autoridade, é possível destacar algumas características comuns entre os "fiéis comandados": a primeira é a impessoalidade, a segunda é a de ser um/a representante do poder, a autoridade, independentemente do cargo que exerce. Ambas podem ser encontradas nas estruturas da Máquina. Tais atitudes comportamentais correspondem ao que Robert Merton tratou como "disfunções da burocracia", que, conforme o conceito de Veblen, traduzem-se na "incapacidade treinada", ou, ainda, no conceito de Dewey de "psicose ocupacional". ${ }^{25}$

Ora, na ambivalência das relações entre os "fiéis comandados" e os "clientes" (tratados por "utentes") reside uma fonte de conflitos, posto que a insistência no comportamento estereotipado que a Máquina sustenta, corroborando o mínimo envolvimento com os problemas individuais, os casos particulares dos indivíduos, acaba por não corresponder à resolução dos problemas sociais. Ao contrário, pode manter ou instaurar outros mas, concomitantemente, salvaguarda a própria estrutura da Máquina burocrática. E talvez seja esta a máxima do jogo da Máquina. Mas os "fiéis comandados" não são também cidadãos e cidadãs?

Sílvia Mendes (2004) observa que, no âmbito da configuração da União Européia, há ecos da Declaração dos Direitos do Homem e do Cidadão, nomeadamente sob os princípios que se impuseram com a Revolução Francesa. Assim, a Revolução que teve a Razão como símbolo, teve na Declaração dos Direitos do Homem e do Cidadão a retirada do aspecto divino como o Deus que provê a todos e delegou ao Homem uma certa autonomia, de tal sorte que este passasse a viver, politicamente, em sintonia com o Criador. A partir de então, "a nação seria composta pela reunião voluntária das vontades individuais”, porque parte-se do princípio que a "soberania passa a residir na nação" (Mendes 2004: 164). Ora, para Hobbes, aquilo que fundamenta o Estado, o soberano, o Leviathan, e que está no princípio das relações de poder, é algo que está

25 Assim, escreveu Merton: "A incapacidade treinada corresponde à situação em que a preparação pode tornar-se inadequada ao mudar certas condições. A falta de flexibilidade na sua aplicação a um meio em transformação produz desajustes mais ou menos sérios. [...] O conceito de Dewey de psicose ocupacional se baseia, em grande parte, na mesma observação. Como resultado da sua rotina diária, os indivíduos vão adquirindo preferências e antipatias. [...] Essas psicoses se desenvolvem pelas exigências da organização na qual o indivíduo desempenha seu papel ocupacional." (Merton 1966: 100) 
profundamente enraizado na idéia de ordem, de paz, do acima da lei, é mais do que a guerra. É algo que acontece constantemente e em todos os âmbitos, pois é a mais geral de todas as guerras. Mas que guerra é esta? Do forte contra o fraco? Do novo contra o velho? Em Hobbes, é o tipo de guerra de "todos contra todos", uma vez que não se trata de uma guerra marcada por diferenças visivelmente estabelecidas. ${ }^{26}$ Como o formula Foucault, é um estado de "diferença insuficiente" (2006: 101). Sendo assim, os indivíduos são iguais, "sujeitos de direitos naturais". Mas é preciso pensar além do modelo jurídico, da lei "como manifestação fundamental do poder" e buscar as várias formas de poder, nos seus entrecruzamentos, especificidades, convergências; ou seja, concebendo o poder a partir das relações de força, distinguindo "as diferentes técnicas de coacção que ela faz operar" (Foucault 2006: 283).

$\mathrm{Na}$ "sociedade dos indivíduos europeus", marcada por princípios que remontam à tradição, à sociedade agrária, camponesa, recém-liberta da ditadura salazarista, que passou de um Estado autoritário a um Estado democrático, será que foi possível modificar mentalidades e percepções de mundo? Será que em alguns espaços não se vê a real expressão da pendularidade do Estado totalitário presente no Estado democrático, ou práticas democráticas matizadas do totalitarismo ou vice-versa? Ou ainda, como salienta Adriana Bebiano (2002), citando uma justificativa de Salazar perante a solicitação da multinacional Coca-Cola para entrar no território/mercado português, o melhor seria que Portugal permanecesse no estado de harmonioso "atraso"? ${ }^{27}$

Não obstante, no cotidiano, as constantes "perturbações" que afligem as pessoas se refletem nas relações interpessoais, nas relações sociais, em diferentes espaços. A necessidade do silenciamento através do uso da força ou constrangimento em nome e segundo o princípio da lei, escamoteia o medo e o estranhamento da igualdade. O discurso da igualdade encontra nele próprio o limite para justificar-se (Derrida 2003: 24). Se na democracia o que se pretende é a igualdade na diferença, entretanto, quando as identidades sob pressão são constrangidas a uma existência de massacre da diferença, silenciando assim suas características intrínsecas, vê-se repondo o que Foucault denominaria de

26 " $[\ldots]$ mesmo aquele que é um pouco mais fraco do que outros, do que um outro, encontra-se ainda assim suficientemente forte para não ter de ceder. Por conseguinte, o fraco nunca renuncia. Quanto ao forte, que é simplesmente um pouco mais forte do que os outros, nunca é suficientemente forte para não ser inquietado e, por conseguinte, para poder deixar de estar vigilante. A indiferenciação natural cria portanto incertezas, riscos, acasos, e, consequentemente, a vontade, de um lado e de outro, de se enfrentarem; é o aleatório na relação primitiva das forças que cria esse estado de guerra" (Foucault 2006: 101).

27 Palavras de Salazar: "Portugal é um país conservador, paternalista e - Deus seja louvado - 'atrasado'. O senhor arrisca-se a introduzir em Portugal aquilo que eu detesto acima de tudo, ou seja, o modernismo e a famosa 'efficiency'. Estremeço perante a ideia dos vossos camiões a percorrer, a toda a velocidade, as ruas das nossas velhas cidades, acelerando, à medida que passam, o ritmo dos nossos hábitos seculares" (em Bebiano 2002: 519). 
"biopoder", "matando" o desejo do outro/estranho e a si mesmo, porque também se aspira à diferença e, ao identificá-la noutro, a assimilo e a neutralizo. Logo, a idéia de ser diferente, de ver satisfeita, em si, a diferença, se torna muito perigosa. Noutra direção, esta mesma idéia pode também recobrar o desejo da (in)diferença por parte principalmente dos que reivindicam sua existência na diferença, quando o reconhecimento e a aceitação da diferença já está interiorizado e, portanto, aquele/a que reconhece o outro não o faz por imposição ou constrangimento, mas o reconhece na totalidade do sujeito/indivíduo que existe.

Finalizando, espera-se que estes poucos exemplos de experiências de distintos sujeitos sociais - incluindo o meu próprio - sejam fecundos para se pensar sobre a compreensão que temos (ou não temos) acerca dos nossos deveres e direitos, na vida em sociedade, nos dias atuais. No conjunto, quis demonstrar que os cidadãos e cidadãs, estrangeiros e portugueses, em Portugal, não estão isentos das "malhas" ou dos caprichos da Máquina burocrática. Todavia, tal observação não ameniza ou serve para mascarar as implicações destes mesmos sujeitos na manutenção do sentido de autoridade numa "situação social". Se este sentido se mantém despótico, talvez a representação que se tem de autoridade, nesta sociedade ou mesmo em outras, ainda não tenha mudado. Assim sendo, e porque este ensaio suscita muitas outras indagações à espera de respostas através de uma pesquisa mais apurada e contrastante com o outro lado da moeda, o das versões daqueles que formulam as "normas", fica aberto, portanto, um campo para investigar sobre tais marcações presentes nas ações dos sujeitos, vendo o que fortalece as arbitrariedades e contribui para a "domesticação" ou o acirramento dos conflitos, no âmbito das relações de força. Ao fazer este tipo de sugestão quero simplesmente "detonar" processos de reflexão e problematização, suscitando o debate e o "estranhamento" de práticas e ações tidas como "naturais", subvertendo o cotidiano e as nossas fórmulas para interpretá-lo, por vezes acomodadas, de tal forma que dos tentáculos do polvo cheguemos à sua cabeça: o Estado. 


\section{BIBLIOGRAFIA}

ARCHETTI, Eduardo P., 1999, "Prologue”, em Eduardo P. Archetti, Masculinities: Football, Polo and the Tango in Argentina. Nova Iorque, Berg, 11-15.

AUGÉ, Marc, 1994, Não-Lugares: Introdução a uma Antropologia da Sobremodernidade. Venda Nova, Bertrand Editora, trad. Lúcia Mucznik.

BEBIANO, Adriana, 2002, "A invenção da raiz: representações da nação na ficção portuguesa e irlandesa contemporâneas", em M. I. Ramalho e A.S. Ribeiro (orgs.), Entre Ser e Estar: Raizes, Percursos e Discursos da Identidade. Porto, Edições Afrontamento, 503-537.

CABRAL, João de Pina, 2005, "Aprender a representar: a democracia como prática local", Novos Estudos CEBRAP, 71: 145-160.

CABRAL, Manuel Villaverde, 1992, "Portugal e a Europa: diferenças e semelhanças", Análise Social, XXVII (1 18-1 19): 943-954.

COSTA, Ricardo da, e Adriana ZIERER, s/d., "Boécio e Ramon Llull: a Roda da Fortuna, princípio e fim dos homens", em < http:/www.hottopos.com/convenit5/08.htm> (consultado em 17/10/2007).

DECLARAÇÃO DE RIVAS, 2006, II Fórum Social Mundial das Migrações, realizado em Rivas Vaciamadrid (Espanha), 22-24 de Junho de 2006, em < http://www.cami-spm.org/download_doc/declaracao_de_rivas.doc> (consultado em 19/03/2009).

DERRIDA, Jacques, 2003, Força de Lei. Porto, Campo das Letras.

DIÁRIO DE NOTÍCIAS, 2007, "Portugueses querem dinheiro bem gasto", em <http://dn. sapo.pt/2007/10/30/economia/portugueses_querem_dinheiro_gasto.html > (consultado em 30/10/2007).

FELDMAN-BIANCO, Bela, 2002, "Portugueses no Brasil, brasileiros em Portugal: antigas rotas, novos trânsitos e as construções de semelhanças e diferenças culturais", em M.I. Ramalho e A. S. Ribeiro (orgs.), Entre Ser e Estar: Raízes, Percursos e Discursos da Identidade. Porto, Edições Afrontamento, 142-184.

FOUCAUlT, Michel, 2006, É Preciso Defender a Sociedade: Curso no Collège de France (1975-1976). Porto, Editora Livros do Brasil.

GIL, José, 2004, O Medo de Existir. Lisboa, Relógio D’Água.

GOFFMAN, Erving, 1993, A Apresentação do Eu na Vida de Todos os Dias. Lisboa, Relógio D’Água. GUSMÃo, Neusa M. M. de, 2004, Os Filhos da África em Portugal: Antropologia, Multiculturalidade e Educação. Lisboa, Imprensa de Ciências Sociais.

HOBSBAWM, Eric, 1997, "Introdução”, em Eric Hobsbawm e Terence Ranger (orgs.), A Invenção das Tradições. Rio de Janeiro, Paz e Terra, 9-24.

LAGES, Mário, et al., 2006, "Os imigrantes e a população portuguesa: imagens recíprocas (análise de duas sondagens)”, Observatório da Imigração, 21 , Lisboa.

MARTINS, José de Souza, 1999, "O decoro nos ritos de interação na área metropolitana de São Paulo”, em José de Souza Martins (org.), Vergonha e Decoro na Vida Cotidiana da Metrópole. São Paulo, Editora Hucitec, 9-16.

MENDES, Sílvia, 2004, "A Europa, os direitos e a cidadania: o passado, o presente e o futuro", Cultura, 19: 161-180.

MERTON, Robert King, 1966, "Estrutura burocrática e personalidade", em Edmundo Campos (org. e introd.), Sociologia da Burocracia (Textos de Weber, Hall, Udy, Gouldner, Terrien, Mills, Hopkins, Eisenstadt, Selznick, Michels, Merton e Blau). Rio de Janeiro, Jorge Zahar Editor, 96-110. 
TURNER, Victor, 1975, Drams, Fields and Metaphors: Symbolic Action in Human Society. Ithaca (NY), Cornell University Press.

VALA, Jorge, Rodrigo BRITO, e Diniz LOPES, 1999, Expressões dos Racismos em Portugal. Lisboa, Instituto de Ciências Sociais.

WEBER, Max, 1966, "Os fundamentos da organização burocrática: uma construção do tipo ideal”, em Edmundo Campos (org. e introd.), Sociologia da Burocracia (Textos de Weber, Hall, Udy, Gouldner, Terrien, Mills, Hopkins, Eisenstadt, Selznick, Michels, Merton e Blau). Rio de Janeiro, Jorge Zahar Editor, 9-15.

—, 2005, Conceitos Sociológicos Fundamentais. Lisboa, Edições 70, trad. Artur Morão.

In the arms of a kind octopus: bureaucracy, authority, citizenship - Vanda Aparecida da Silva - Instituto de Ciências Sociais (UL); Centro de Estudos Rurais (UNICAMP) - vanda. aparecida@ics.ul.pt

This is an essay inspired by experiences of Portuguese and foreign citizens, including the ones of the foreign researcher who writes it, in dealing with agencies of the administrative Machine of the host country, Portugal. My intention is here to understand some devices of the bureaucracy in daily life and discuss some of the uses of the meaning of authority in social relations. The text begins with notes of an "autobiographic ethnography", while examining such social relations and the ways they can be affected by complex dynamics of establishment and incorporation of bureaucratic norms. The text brings elements that contribute for the understanding and reflection on the processes of learning citizenship, along with the expressions and representations of authority in a social situation.

KEYWORDS: bureaucracy, authority, citizenship, management administration. 